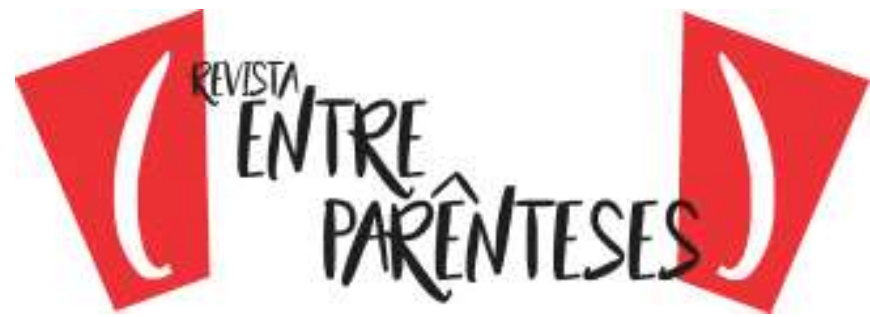

\section{METÁFORAS CONCEITUAIS EM JAMAICA KINCAID: BREVE ANÁLISE SOBRE A AUTOAFIRMAÇÃO IDENTITÁRIA CARIBENHA ${ }^{1}$}

\author{
https://doi.org/10.32988/rep.v2n9.1211
}

\author{
Gildeon Alves dos Santos ${ }^{2}$ \\ Universidade Federal da Bahia/FAPESB \\ (gildeon_alves@hotmail.com)
}

\begin{abstract}
Resumo: O presente artigo apresenta uma breve análise de duas metáforas conceituais presentes nas narrativas da escritora caribenha Jamaica Kincaid. Objetiva-se, aqui, a tessitura de uma discussão, à luz da teoria da metáfora conceitual (LAKOFF; JOHNSON, 1980), de questões de autoafirmação identitária caribenha em três textos da autora, a saber: On seeing England for the first time (1991), Annie John (1997) e A Small Place (2000). Essas discussões sobre identidade são, em linhas gerais, revisitadas em textos teóricos de três dos principais escritores daquela região, Frantz Fanon, Stuart Hall e Édouard Glissant, para estabelecer uma contextualização temática destes com as obras anteriormente mencionadas. Por fim, promove-se rápida reflexão sobre como a experiência da colonização e do deslocamento incide nas construções identitárias daqueles povos.
\end{abstract}

Palavras-chave: Colonização; Autoafirmação Identitária; Metáfora Conceitual.

\section{CONCEPTUAL METAPHORS IN JAMAICA KINCAID: SHORT ANALYSIS ON THE CARIBBEAN SELF-AFFIRMATION IDENTITY}

Abstract: The present paper is a short analysis of two conceptual metaphors in narratives written by the Caribbean author Jamaica Kincaid. Its main objective is discussing, under the light of the conceptual metaphor theory (LAKOFF; JOHNSON, 1980), issues of The Caribbean identity self-affirmation through three works of the author, such as: On seeing England for the first time (1991), Annie John (1997) and A Small Place (2000). It broadly presents some of the most common themes in narratives by three of the main scholars of that region, namely, Frantz Fanon, Stuart Hall and Édouard Glissant, in the attempt to establish a thematic contextualization of those with the work above mentioned. Finally, it rises short reflection on how the experience of colonization and displacement affect the identity construction of those people.

Keywords: Colonization; Identity Self-affirmation; Conceptual Metaphor.

\section{METÁFORAS CONCEPTUALES EN JAMAICA KINCAID: UN BREVE ESTUDIO SOBRE LA AUTOAFIRMACIÓN IDENTITARIA CARIBEÑA}

\footnotetext{
${ }^{1}$ As discussões, aqui, propostas nascem da pesquisa desenvolvida durante o Mestrado em Língua e Cultura e dialogam com considerações apresentadas na dissertação de Mestrado intitulada Ressignificando Bob Marley: um estudo sobre a tradução de metáforas, disponível em: https://repositorio.ufba.br/ri/bitstream/ri/31561/1/DISSERTAO_PS-DEFESA_final.pdf.

2 Professor efetivo de Língua Inglesa na Secretaria de Educação do Estado da Bahia (SEC); Diretor do Centro Territorial de Educação Profissional do Piemonte da Diamantina II (NTE - 16 Jacobina). Mestre em Língua e Cultura (PPGLinC) pela Universidade Federal da Bahia (UFBA); Especialista em Metodologia da Pesquisa e Ensino de Língua Inglesa pela Faculdade Católica de Anápolis (FCA); Graduado em Letras Língua Inglesa e Literaturas pela Universidade do Estado da Bahia (UNEB).
} 


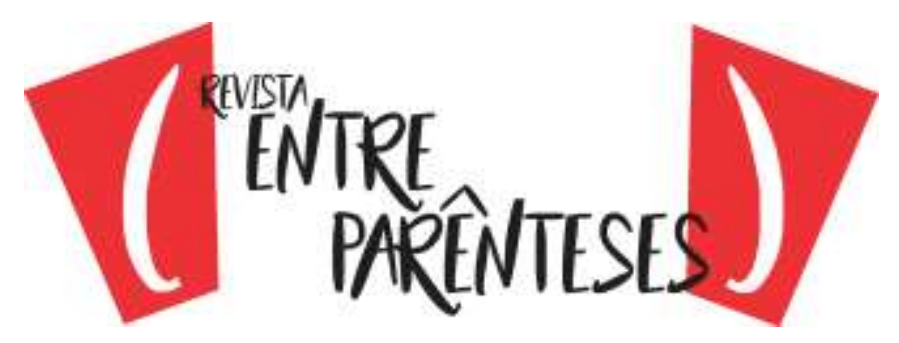

Resumen: El presente artículo es un breve análisis de dos metáforas conceptuales en las narraciones de la escritora caribeña Jamaica Kincaid. Su principal objetivo es discutir, bajo la óptica de la teoría de la metáfora conceptual (LAKOFF; JOHNSON, 1980), cuestiones de afirmación identitaria caribeña a través de tres obras literarias de la autora: On seeing England for the first time (1991), Annie John (1997) y A Small Place (2000). De forma general, expone algunos de los temas más comunes en las narraciones de tres de los principales eruditos en esta región, en particular, Frantz Fanon, Stuart Hall y Édouard Glissant, en un intento de establecer una contextualización temática entre ellas y el trabajo indicado precedentemente. Por fin, se levanta cuestiones sobre como la experiencia de la colonización impacta en la construcción de la identidad de estos pueblos.

Palabras-clave: Colonización; Autoafirmación Identitaria; Metáfora Conceptual.

\section{PARA INÍCIO DE CONVERSA: A TEORIA DA METÁFORA CONCEITUAL}

Distanciando-se do tensionamento entre linguagem figurada e linguagem literal, os autores Lakoff e Johnson (1980) desenvolvem a teoria da metáfora conceitual, partindo do princípio de que a metáfora é um processo cognitivo que permeia a linguagem do cotidiano. No primeiro capítulo de Metaphors we live by (1980), George Lakoff e Mark Johnson discorrem sobre a forma como o sistema cognitivo humano é caracterizado e sobre sua relação com o entendimento de metáforas. Eles afirmam que o nosso sistema conceitual é naturalmente metafórico, sendo que a forma como agimos e pensamos estrutura-se a partir da nossa percepção de mundo, do modo como interagimos com ele e com as outras pessoas em nosso cotidiano. No entanto, pensamos e agimos de forma automática, sem termos consciência disso.

Assim, para os autores, a metáfora deixa de ser apenas um recurso retórico para o embelezamento do discurso, mas compõe o próprio sistema conceitual de cada um de nós. Isso explica a razão pela qual as pessoas entendem as metáforas, pois, uma vez que a comunicação é realizada por meio do sistema conceitual, seria possível perceber, no uso da linguagem, as várias situações em que um conceito é metafórico no seu uso cotidiano. Daí a ideia de "metáfora conceitual". 


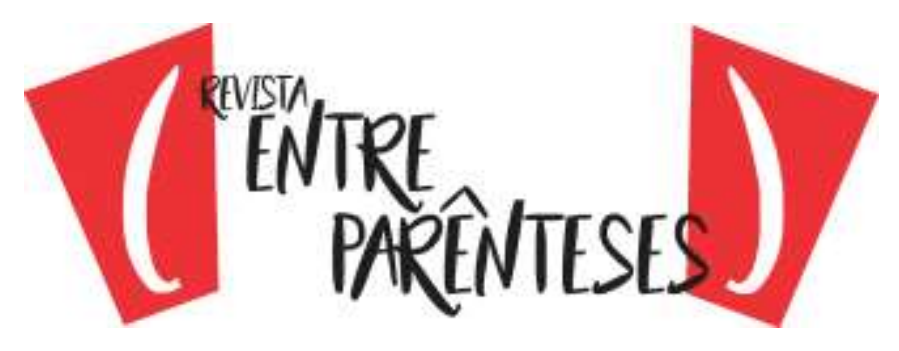

Para exemplificar o conceito de "metáfora conceitual", esses autores utilizam a metáfora AMOR É UMA VIAGEM ${ }^{3}$, em que se realiza um mapeamento de AMOR COMO VIAGEM, destacando quatro correspondências ontológicas presentes nesses dois domínios: AMOR e VIAGEM. Estas são:

I) Os amantes correspondem aos viajantes;

II) A relação amorosa corresponde ao veículo;

III) O foco comum dos amantes corresponde aos seus pontos de chegada em uma viagem;

IV) Dificuldades na relação correspondem a impedimentos para viajar.

Tais correspondências, no entanto, não são parte da gramática, nem do léxico, mas estão na mente do enunciador, que possui um conhecimento básico e empírico dos dois domínios cognitivos: AMOR e VIAGEM. É, para Lakoff e Johnson, este conhecimento que, ligado à experiência do falante e do ouvinte, permite o entendimento das expressões linguísticas: (I) Estamos em uma encruzilhada; (II) Talvez tenhamos que tomar caminhos diferentes; e (III) O relacionamento não vai a lugar algum - como sendo metáforas referentes a um relacionamento amoroso, visto que essas, em outros contextos, podem ser entendidas de diferentes formas. Inclusive no assim chamado sentido literal.

No texto The contemporary theory of metaphor (1992), Lakoff rejeita as teorias clássicas da linguagem, que concebem a metáfora como sendo um recurso meramente linguístico e separado do uso cotidiano. Para o autor, a metáfora é, em primeiro lugar, conceitual e convencional, uma vez que faz parte do sistema comum do pensamento e da linguagem.

As metáforas também revelam conceitos, convenções, pensamentos e ideologias, além de estarem ligadas às experiências cognitivas e culturais de cada indivíduo. As metáforas conceituais que aqui serão analisadas podem ser consideradas instrumentos cruciais para melhor compreensão das manifestações

\footnotetext{
${ }^{3} \mathrm{O}$ sintagma em caixa alta é a forma que os autores escolheram para diferenciar a Metáfora Conceitual (o modelo estruturado em nosso cérebro, de forma inconsciente) das demais metáforas utilizadas com a finalidade de embelezar a língua, tornando-a mais floreada, mais atraente.
} 


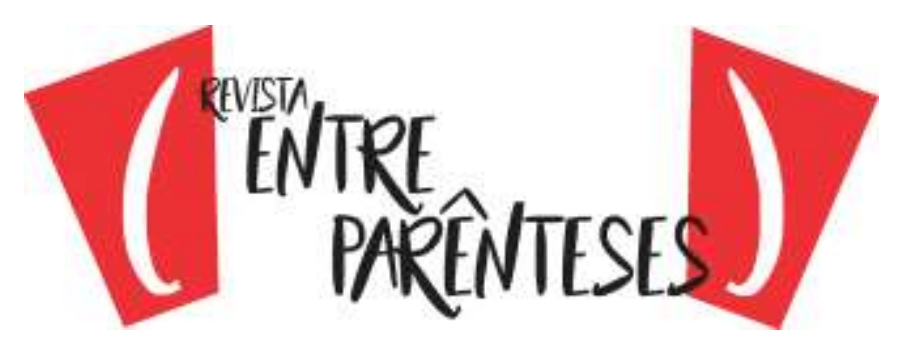

artísticas e culturais de um povo, bem como de suas ideologias e significação do mundo a sua volta. É com base nessa teoria, portanto, que propomos uma breve discussão de textos de Jamaica Kincaid sob a ótica das metáforas conceituais, por considerá-las narrativas prenhes de significados, na medida em que tal teoria contribui para identificação e análise de questões referentes à autoafirmação identitária dos povos caribenhos.

\section{SOBRE AS NARRATIVAS CARIBENHAS}

Antes de iniciarmos as análises supracitadas, e tendo em vista o caráter cognitivo e cultural das metáforas conceituais, faz-se necessária uma breve retomada ao contexto histórico e artístico cultural em que estão inseridas algumas das obras da escritora Jamaica Kincaid. É necessário ressaltar que, nesta seção, não temos a pretensão de traçar um panorama completo das narrativas caribenhas, pois, se assim o fizéssemos, estaríamos extrapolando os objetivos do presente artigo. No entanto, julgamos necessário citar duas figuras que se mostram muito pertinentes para 0 entendimento do contexto em que tais narrativas foram criadas, das temáticas recorrentes em seus textos e para melhor compreensão das metáforas nas narrativas posteriormente analisadas.

Para começar, ressaltamos a relevância do pesquisador Franz Fanon, que, nascido em 1925, na llha de Martinica, ficou conhecido por sua militância na Segunda Guerra Mundial, quando foi condecorado diversas vezes em virtude da sua bravura em combate. Com formação em psiquiatria e filosofia na França, Fanon discute sobre questões políticas e sociais, com ênfase na transformação com vistas à melhoria da vida de grupos sociais (negros) vítimas do sistema hegemônico de governo durante o Período Colonial. O autor também deixou um legado de quatro obras publicadas: Pele negra, máscaras brancas, publicada em 1952; $O$ ano $V$ da revolução argelina, em 1959; Os condenados da terra, em 1961; e Para a revolução africana, em 1964, sendo esta última editada postumamente por sua esposa Josie Fanon. 


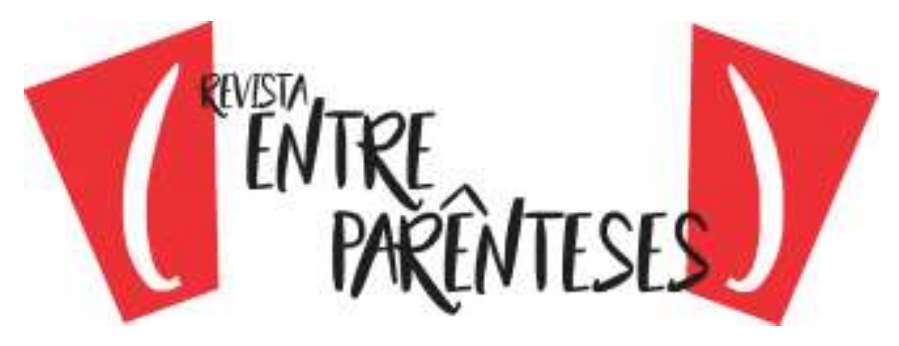

Em Pele negra, máscaras brancas, Fanon (2008) reflete sobre os impactos do Período Colonial nas identidades dos negros martinicanos, dando ênfase à forma como as teorias que defendem a supremacia branca europeia reverberam no comportamento do negro martinicano, tanto em relação à língua quanto em relação à cultura da metrópole: França.

No primeiro capítulo, o autor discute sobre o complexo de inferioridade dos martinicanos em relação à língua francesa. Ele diz que

[...] o negro antilhano será tanto mais branco, isto é, se aproximará mais do homem verdadeiro, na medida em que adotar a língua francesa [...]. Um homem que possui a linguagem possui, em contrapartida, o mundo que essa linguagem expressa e que lhe é implícito [...] [pois] existe na posse da linguagem uma extraordinária potência (FANON, 2008, p. 34).

Importante notar que a citação supramencionada alude a uma descrição, ou seja, não é uma afirmação que o autor considere modelo ideal de comportamento. Ele apenas relata como têm sido as relações colônia versus metrópole, com vistas a apontar excessos presentes em tais relações. Em outras palavras, ele não afirma que a língua francesa e a branquitude caracterizarão o que é verdadeiramente o homem, mas salienta que esse discurso se fazia presente nas Antilhas dos anos 1950 e que sua compreensão é essencial no desenvolvimento de estratégias para combatê-lo.

Após identificar a problemática da relação colônia versus metrópole, o estudioso se debruça sobre a experiência do deslocamento. Ele diz haver certo fascínio do morador da colônia em relação à sua metrópole e que isso fica evidente quando ele vive a experiência de sair do lugar onde nasceu para viver na metrópole. Da mesma forma, quando o nativo da colônia, já com a vivência pregressa na metrópole, volta para sua cultura de origem este back ground fica bastante evidente, sobretudo no uso que este faz da linguagem e com qual cultura ele quer ser identificado. É essa mudança de personalidade que, relacionada à experiência do deslocamento, interessa a Fanon, que faz os seguintes questionamentos: 


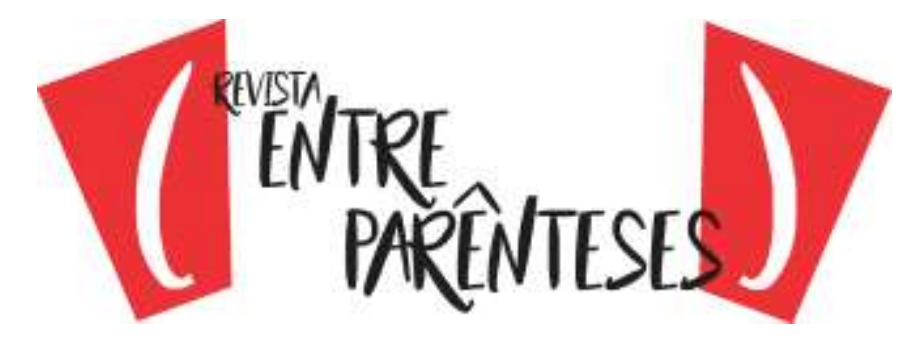

De onde provém esta alteração da personalidade? De onde provém este novo modo de ser? Todo idioma é um modo de pensar, dizem Damourette e Pichon. E o fato de um negro recém-chegado adotar uma linguagem diferente daquela da coletividade em que nasceu representa um deslocamento, uma clivagem. $O$ professor Westermann, em The African Today, escreveu que existe um sentimento de inferioridade entre os negros, principalmente entre os "evoluídos", que eles tentam permanentemente eliminar (FANON, 2008, p. 39-40).

Aqui, o estudioso se refere àquele negro antilhano que, após morar por certo tempo na França, retorna à Martinica com o discurso de que não mais se recorda do crioulo. Concordando com a ideia de que todo idioma é um modo de pensar, temse que o modo de pensar de tal migrante está muito mais influenciado pela filosofia da França, onde ele passou apenas determinado tempo, do que pela vida na Martinica, seu país de origem. Fanon identifica nessa alteração de personalidade um complexo de inferioridade, que, segundo ele, advém da experiência migratória. Ocorre que, estando na colônia, o negro tem sua cultura, valores, crenças e filosofias silenciadas pela hegemonia da metrópole. Isso faz com que ele veja na cultura do colonizador o modelo ideal de civilização e passe a desprezar sua própria cultura. Ao chegar à metrópole, como estratégia para escapar do preconceito sofrido por aqueles que trazem na linguagem as características de um provinciano, ele tende a abrir mão dessas identidades que o ridicularizam e tenta ficar o mais semelhante possível ao colonizador.

De volta para seu país de origem, esse migrante precisa lidar com uma série de situações relacionadas às mudanças que ocorreram na sua identidade. Para seus amigos metropolitanos, ele não passa de um provinciano que tenta imitar o homem branco civilizado europeu, enquanto que seus patrícios o veem com desconfiança por perceberem, na personalidade desse sujeito, certo grau de uma pseudossuperioridade, isto é, percebem nele alguém que menospreza a cultura da sua gente em favor da de outro grupo social, por achá-lo superior e mais interessante.

Essa alteração de personalidade do negro colonizado discutida acima dialoga com os Estudos Culturais mais recentes, sobretudo aqueles que abordam a problemática das construções identitárias na assim chamada pós-modernidade. 


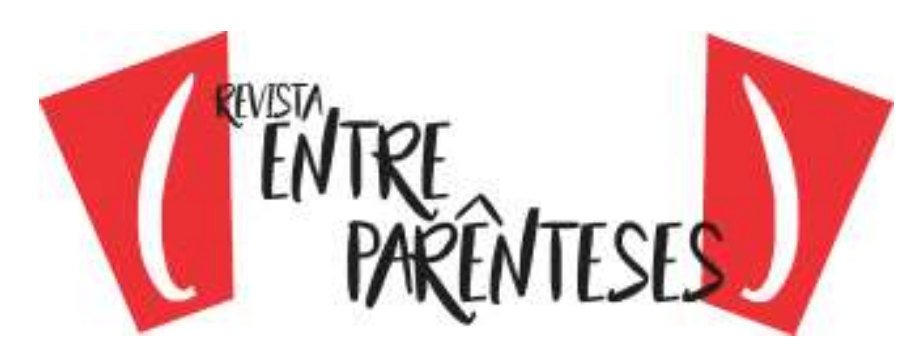

Dentre vários outros estudiosos que discutem essa temática, nas ilhas caribenhas, temos os trabalhos de Stuart Hall.

Nascido em 1932 na Jamaica, Stuart Mcphail Hall tornou-se mundialmente conhecido no final da década de 1970 quando, já na Inglaterra, se mostrou um crítico severo do governo conservador da então ministra britânica Margaret Thatcher. Sendo um dos principais nomes dos Estudos Culturais, Hall se interessa por estudos que dão conta de como as instituições sociais interferem na cultura de um povo e na construção de significados entre os indivíduos de grupos diversos. Suas principais obras são: The Popular Arts, de 1964; Deviancy, Politics and the Media, de 1971; Encoding and Decoding in the Television Discourse, de 1973; A 'Reading' of Marx's, 1857; Introduction to the Grundrisse, de 1973; The Hard Road to Renewal: Thatcherism and the Crisis of the Left, de 1988; Representation: Cultural Representations and Signifying Practices, de 1997; Gramsci's Relevance for the Study of Race and Ethnicity, de 1986; Cultural Studies and Its Theoretical Legacies, de 1992; e uma publicação em língua portuguesa no Brasil, Da diáspora: identidades e mediações culturais, de 2013. A ideia desse último título tomou corpo na ocasião da viagem de Hall à Bahia no ano 2000.

O primeiro capítulo de Da diáspora: identidades e mediações culturais, intitulado "Pensando a diáspora: reflexões sobre a terra no exterior", é uma tradução para a língua portuguesa de uma palestra de Stuart Hall na ocasião do quinquagésimo aniversário da Universidade das Índias Ocidentais em Barbados, no ano de 1998. Nele, o autor, a partir de suas experiências diaspóricas e de algumas décadas de pesquisas na área dos Estudos Culturais, aborda a problemática da diáspora caribenha, com enfoque na construção da nação e das identidades caribenhas na era da globalização.

A partir do conceito de comunidades imaginadas, de Benedict Anderson, que, numa perspectiva antropológica, diz ser nação "uma comunidade política imaginada - e imaginada como sendo intrinsecamente limitada e, ao mesmo tempo, soberana" (ANDERSON, 2008, p. 32), Hall se debruça sobre questões que estão além de uma ideia de nação fundamentada nos limites políticos e geográficos. Ele segue 


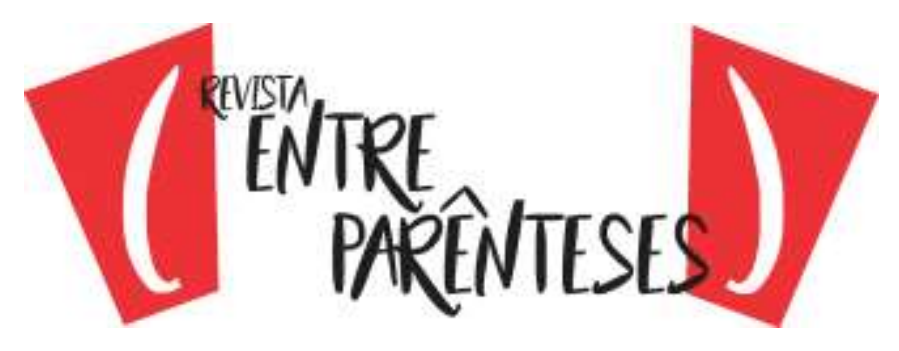

em direção às relações que os sujeitos estabelecem com sua "[...] terra de origem, e a natureza do seu 'pertencimento'” (HALL, 2013, p. 28). Segundo o autor, a questão das identidades caribenhas pós-independência é de suma importância, sobretudo para as produções artísticas, visto que se trata de uma região povoada por pessoas de diversas etnias, línguas e culturas. Para tanto, Hall destaca o papel das fronteiras históricas, culturais, geográficas etc., numa tentativa de demonstrar os reflexos dessas fronteiras nas identidades caribenhas, levando em consideração o contexto da experiência do deslocamento na pós-modernidade.

Conclui com um alerta às emergentes culturas diaspóricas para o risco de copiar o modelo imperialista em que o centro determina o padrão de comportamento e a periferia o segue. Segundo Hall, este é um risco iminente, uma vez que as culturas emergentes, em especial as caribenhas, são constantemente ameaçadas pelo hibridismo, o que pode desencadear uma centralidade nelas mesmas e a construção de novas barreiras de proteção. Para o autor, esse velho modelo eurocêntrico já está falido, razão pela qual ele sugere uma abordagem de cultura mais eclética, baseada no que ele chama de "jogo da semelhança e da diferença" (HALL, 2013, p. 52), em que culturas diferentes, mas com características comuns, estão se fortalecendo a partir das trocas de experiências entre si, configurando, assim, o que se pode chamar de povo culturalmente sensível na dita era pós-moderna.

Nesse mesmo sentido, o antilhano Édouard Glissant (2005) desenvolve o conceito de "crioulização". Para o autor, tal fenômeno ocorre quando dois elementos culturais totalmente distintos são colocados em contato, tendo como resultado um terceiro elemento totalmente imprevisível. Foi o que ocorreu, por exemplo, na Europa, onde povos de diferentes comunidades linguísticas se encontraram, dando origem ao que hoje se conhece como língua francesa, língua inglesa, língua portuguesa etc. Aproveitando este mesmo exemplo, Hall (2013) chama a atenção para o fato de que, no caso das línguas e culturas europeias, o reconhecimento do elemento novo imprevisível deu-se através da violência, visto que grupos invasores e saqueadores de comunidades alheias, ao se estabelecerem nelas, impunham sempre seus costumes, suas línguas e ideologias, classificando como bárbaro e selvagem tudo o 


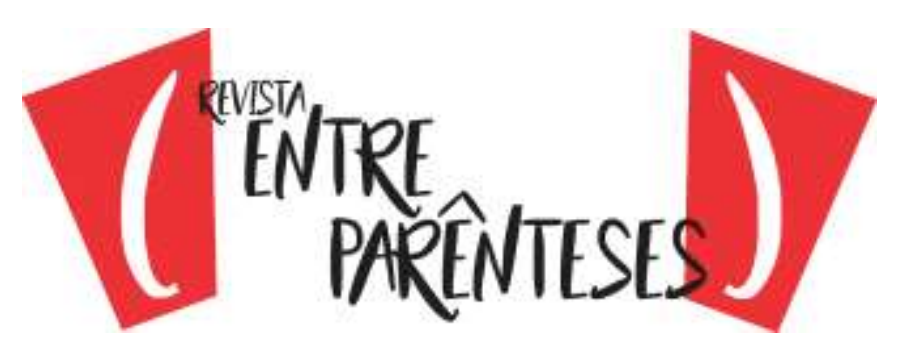

que remetia à comunidade invadida. Tal violência é, portanto, o modelo alvo de crítica por parte dos autores supramencionados.

Em síntese, não seria coerente, no contexto global contemporâneo, discorrer sobre uma identidade caribenha raiz, isolada de outros povos de fora do Caribe. Glissant segue numa direção diversa, quando, na discussão sobre as identidades caribenhas, toma emprestado de Deleuze e Guattari o conceito de rizoma em oposição ao de raiz única. "A raiz única é aquela que mata à sua volta, enquanto o rizoma é a raiz que vai ao encontro de outras raízes" (GLISSANT, 2005, p. 61). As identidades caribenhas, portanto, nessa perspectiva, seriam rizomáticas, nem submissas às origens hegemônicas das metrópoles, nem fechadas em si mesmas.

\section{CÓPIA DE MODELOS: ANÁLISE DAS METÁFORAS CONCEITUAIS METRÓPOLE É MÃE E COLÔNIA É FILHA EM NARRATIVAS DE KINCAID}

A cópia do modelo hegemônico de comportamento da metrópole é também um assunto que interessa a uma notável escritora caribenha: a antiguana Jamaica Kincaid. Nascida em St. John, Antígua, em 1949, quando foi batizada com o nome de Elaine Potter Richardson, Jamaica Kincaid é reconhecida mundialmente por sua escrita irreverente, carregada de ironia, em que as imagens da colonização europeia são constantemente (re)construídas a partir do ponto de vista daqueles que tiveram suas línguas e costumes marginalizados, criminalizados e colocados em segundo plano pelo estilo hegemônico das metrópoles europeias. Possui uma diversidade de material publicado, sendo cinco romances, uma coletânea de contos e vários artigos e ensaios publicados em revistas.

Em um dos seus romances, Annie John (1997), através da personagem homônima, Kincaid narra a história de uma garota negra e sua curiosa relação com a mãe, as amigas, a escola e a igreja em Antígua. Aborda temas tais como a relação mãe e filha, a sexualidade e o papel da escola e da igreja na formação das identidades, sem perder de vista os conflitos culturais e identitários causados pela 


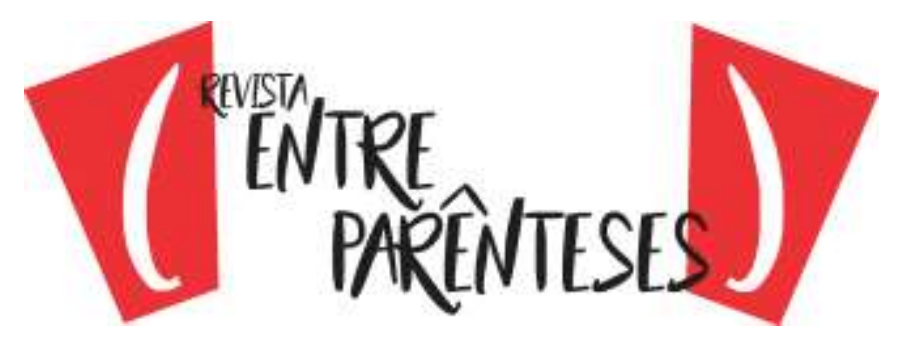

imposição de um estilo de vida europeu branco no contexto de uma colônia tropical, de maioria negra.

No que diz respeito à relação da personagem com sua mãe, a autora apresenta pelo menos duas fases distintas: a primeira fase, pré-puberdade, é marcada pela boa relação entre mãe e filha, pela admiração de Annie John por sua mãe, conforme podemos observar a seguir:

[...] Enquanto minha mãe preparava nosso jantar, pegava as roupas que estavam nas pedras, ou tirava as roupas do varal, eu sentava em um canto e a observava. Ela nunca ficava parada. Suas pernas fortes a levavam de uma parte do quintal para outra, e para dentro e para fora da casa. [...]. Às vezes, quando eu lhe dava as folhas para o chá, ela se abaixava e beijava meus lábios, depois meu pescoço. Era em um paraíso desses que eu vivia (KINCAID, 1997, p. 25, tradução nossa). ${ }^{4}$

Podemos constatar, na citação acima, que a protagonista observa sua mãe em detalhes: porte físico, movimentos e atitudes. A figura da mãe é um exemplo a ser seguido. Alguém que sabe recompensar, com carinho, aqueles que lhe prestam algum serviço, tornando a convivência harmoniosa e agradável, comparada ao paraíso.

Já na segunda fase, pós-puberdade, essa harmoniosa relação entra em crise. Annie John se torna uma adolescente e, por conta disso, sua mãe a encaminha para as aulas ditas de "boas maneiras" para que a filha aprenda a se comportar em sociedade. Infelizmente, para Annie John, essas aulas de boas maneiras, inspiradas nos costumes europeus, não são exatamente as coisas com as quais ela estava acostumada a lidar na ilha. Diante de sua recusa, a mãe se sente frustrada de tal forma que essa frustração se revela em seu comportamento em relação à filha, o que a surpreende, conforme se percebe no trecho a seguir:

\footnotetext{
4 "[...] As my mother went around preparing our supper, picking up clothes from the stone heap, or taking clothes off the clothes-line, I would sit in a corner and watch her. She never stood still. Her powerful legs carried her from one part of the yard to the other, and in and out of the house [...]. Sometimes, when I gave her the herbs, she might stoop down and kiss me on my lips and then on my neck. It was in such paradise that I lived" (KINCAID, 1997, p. 25).
} 


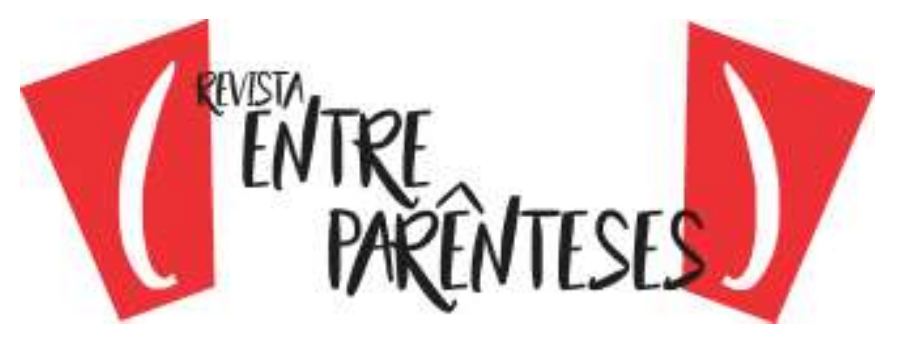

[...] Quão novo era isso pra mim: as costas da minha mãe viradas pra mim em sinal de desgosto. De fato, eu não passava todos os meus dias ao lado da minha mãe antes disso, [...] mas antes desse negócio de 'mocinha' eu podia sentar e pensar em minha mãe, vê-la fazendo uma coisa ou outra, e sempre no rosto dela tinha um sorriso para mim. Agora, eu sempre a via com um sorriso de canto de boca me desaprovando (KINCAID, 1997, p. 28, tradução nossa). ${ }^{5}$

A relação mãe e filha aqui relatada, dadas suas devidas proporções, lembra a relação metrópole versus colônia. A mãe de Annie John tem uma expressiva influência sobre o comportamento da filha quando esta ainda não atingiu a puberdade. É a mãe quem escolhe o vestido, é a mãe quem gerencia a alimentação. Tal comportamento é análogo ao da metrópole, na medida em que esta, pelo seu poder de compra e hegemonia política, leva para a colônia sua cultura, seus costumes (isso inclui sua gastronomia), e sua forma de ver o mundo. A colônia, por sua vez, como uma filha obediente, segue aquele modelo imposto pela metrópole, sem que lhe seja dada a oportunidade de questioná-lo. Esta é a primeira fase.

Na segunda fase, a colônia, tal como uma filha adolescente rebelde, reage na tentativa de construir uma identidade nacional própria, um sentido de pertencimento, uma valorização da cultura local em detrimento dos costumes e valores impostos pela mãe metrópole. Essa "rebeldia" da colônia, representada pela personagem de Annie John, se percebe na sua recusa às aulas de "boas maneiras", bem como na sua leitura crítica dos diversos eventos históricos estudados na escola. $\mathrm{Na}$ citação abaixo, apresentamos um trecho para ilustrar como essa personagem compreendia um dos tidos como grandes homens da história. O excerto diz respeito à análise que ela faz de uma imagem que registra a deportação de Cristovam Colombo para a Espanha em 1500. Eis o trecho:

A pintura tinha como título "Colombo Acorrentado", impresso na margem inferior da página. O que havia acontecido foi que o habitual

\footnotetext{
5 "[...] What a new thing this was for me: my mother's back turned on me in disgust. It was true that I didn't spend all my days at my mother's side before this, [...] but before this young-lady business I could sit and think of my mother, see her doing one thing or another, and always her face bore a smile for me. Now I often saw her with the corner of her mouth turned down in disapproval of me" (KINCAID, 1997, p. 28).
} 


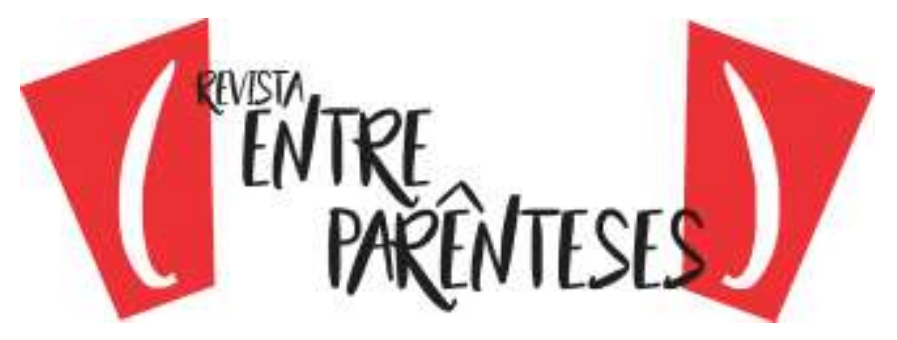

encrenqueiro Colombo havia entrado em desavença com outras pessoas ainda mais encrenqueiras, e um homem chamado Bobadilla, representante do rei Fernando e da rainha Isabella, o havia enviado de volta para a Espanha, cingido por correntes presas ao porão de um navio. Que partida, pensei, pois eu, de fato, não gostava de Colombo. Como amei aquela pintura - ver o costumeiro triunfante Colombo tão rebaixado, sentado no porão do navio a ver as coisas passarem (KINCAID, 1997, p. 77-78, tradução nossa). ${ }^{6}$

Considerando o fragmento, é possível afirmar que Annie John se configura como a tradução antiguana pós-colonial dos eventos históricos registrados pela história oficial, cujo ponto de vista e discurso são preponderantemente europeus. Assim, dadas as condições em que os sobreviventes do período de escravização se encontram, mesmo depois da independência política da ilha, não é de se estranhar que o dito corajoso e grande conquistador Cristóvão Colombo da história oficial seja o déspota encrenqueiro nas narrativas caribenhas.

Em 1991, Jamaica Kincaid escreve On seeing England for the First Time. Nesse ensaio, a autora narra a história de uma mulher que, ainda em sua idade escolar, é apresentada à Inglaterra dos mapas, dos livros didáticos de História e de Geografia, bem como das aulas de Literatura Inglesa. Uma Inglaterra majestosa, comparada à terra prometida, à nova Jerusalém. A estudante cresce revoltada em meio a essa idealização da metrópole. Revoltada, porque os governantes justificavam uma série de arbitrariedades, tanto no âmbito sociocultural como no educativo, baseados nos discursos de uma Inglaterra idealizada. Revoltada contra a imposição da cultura da metrópole inglesa em Antígua. Revoltada, sobretudo, pela forma como os moradores daquela ilha aceitavam, e até se identificavam com a cultura do opressor.

\footnotetext{
6 "The Picture had as a title 'Colombus in Chains', printed at the bottom of the Page. What had happened was that the usually quarrelsome Columbus had got into a disagreement with people who were even more quarrelsome, and a man named Bobadilla, representing King Ferdinand and Queen Isabella, had sent him back to Spain fettered in chains attached to the bottom of a ship. What just deserts, I thought, for I did not like Columbus. How I loved this picture - to see the usually triumphant Columbus, brought so low, seated at the bottom of a boat just watching things go by" (KINCAID, 1997, p. 77-78).
} 
Encantados com a cultura inglesa, os antiguanos muitas vezes tinham um comportamento muito diferente do que se esperava de um habitante de um país tropical. Kincaid, de forma bastante eloquente, descreve situações dessa ordem quando trata dos hábitos do pai da personagem principal, como no fragmento a seguir:

Meu pai, que possivelmente teria se sentado próximo a mim no café da manhã, era um carpinteiro e marceneiro. Os sapatos que ele usava para trabalhar teriam sido feitos na Inglaterra, assim como suas camisas e calças cáqui, suas cuecas e camisetas, suas meias e seu chapéu marrom de feltro. Feltro não era um material apropriado,com o qual um chapéu com a finalidade de oferecer sombra no sol quente deve ser feito, mas meu pai deve ter visto e admirado a foto de um cavalheiro inglês usando esse tipo de chapéu na Inglaterra, e essa foto que ele viu deve ter sido tão atraente que fez com que ele usasse, por quase toda sua longa vida, o chapéu errado para um clima quente (KINCAID, 1991, p. 33, tradução nossa). ${ }^{7}$

No trecho acima percebemos certa aculturação presente no comportamento de parte dos caribenhos antiguanos, que viam na metrópole um modelo a ser copiado, mesmo que para isso fosse necessário se desvencilhar dos seus próprios costumes, das suas próprias culturas, das suas próprias raízes, utilizando "chapéus inadequados para o clima tropical" daquela região.

Já em A Small Place, a colônia, filha que antes ouvia atentamente os ensinamentos da mãe, metrópole, não apenas se rebela como uma adolescente, mas assume a posição daquela cujo exercício de autoconhecimento já se encontra em um nível tão elevado que passa a instruir sua mãe, mostrando que entre a ideia que a mãe tem de sua filha e a forma como esta se reconhece existe um hiato gigantesco.

Publicado em 1988, A Small Place trata-se de uma narrativa escrita em primeira pessoa na qual o narrador, antiguano, apresenta sua cidade ao leitor, um

\footnotetext{
7 "My father, who might have sat next to me at breakfast, was a carpenter and cabinet maker. The shoes he wore to work would have been made in England, as were his khaki shirt and trousers, his underpants and undershirt, his socks and brown felt hat. Felt was not the proper material from which a hat that was expected to provide shade from the hot sun should be made, but my father must have seen and admired a picture of an Englishman wearing such a hat in England, and this picture that he saw must have been so compelling that it caused him to wear the wrong hat for a hot climate most of his long life" (KINCAID, 1991, p. 33).
} 
hipotético turista, norte-americano ou europeu, que, influenciado pelas publicidades das agências de turismo, chega à ilha com uma ideia um tanto ingênua do que de fato é aquele lugar do ponto de vista de quem precisa viver ali. Kincaid descreve em riqueza de detalhes as precárias condições de sobrevivência das pessoas menos favorecidas moradoras da ilha. Ressalta o descaso dos governantes com serviços essenciais, tais como saúde, educação e segurança, apontando indícios claros de corrupção no governo que acabam reverberando nos serviços de transporte público, tanto aéreo quanto terrestre, bem como na falta de insumos básicos para manutenção de patrimônios artísticos e culturais.

O diálogo do antiguano com o turista tem início logo nas primeiras palavras da narrativa, quando o avião do visitante está prestes a aterrissar. Eis a descrição:

Se você for a Antígua como turista, é isto que você vai ver. Se você vier de avião, você aterrissará no Aeroporto Internacional V. C. Vere Cornwall (V.C) Bird é o Primeiro Ministro de Antígua. Você talvez seja o tipo de turista que se perguntaria por que um Primeiro Ministro gostaria de ter um aeroporto com seu nome e - por que não uma escola, por que não um hospital, por que não algum grande monumento público? Você é um turista e ainda não viu o hospital em Antígua, você não viu ainda o monumento público em Antígua (KINCAID, 1988, p. 3, tradução nossa). ${ }^{8}$

Logo nessas primeiras linhas o narrador já dá o seu recado. Ao fazer uma pergunta capciosa, quando questiona a razão pela qual um aeroporto e não uma escola, hospital, ou monumento público recebe o nome do chefe de Estado, desperta a atenção do leitor para uma série de problemas que serão apresentados ao longo da narrativa. Em seguida, sinaliza a ignorância do turista que, nesta condição, desconhece a "real" Antígua.

\footnotetext{
8 "If you go to Antigua as a tourist, this is what you will see. If you come by airplane, you will land at the V.C. Bird International Airport. Vere Cornwall (V.C) Bird is the Prime Minister of Antigua. You may be the sort of tourist who would wonder why a Prime Minister would want an airport named after him - why not a school, why not a hospital, why not some great public monument? You are a tourist and you have not yet seen the hospital in Antigua, you have not yet seen a public monument in Antigua" (KINCAID, 1988, p. 3).
} 


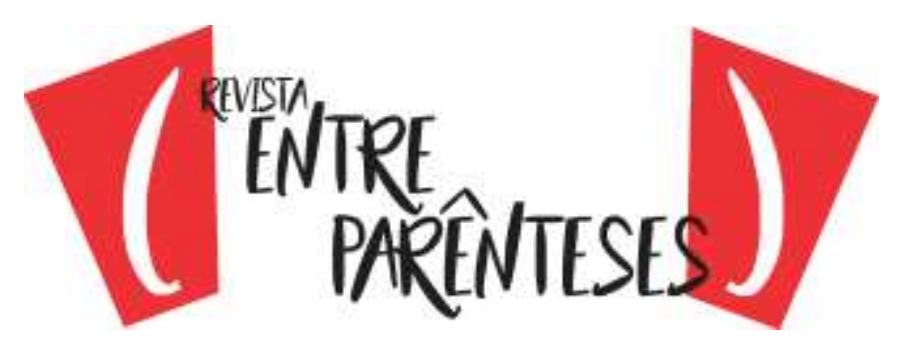

Após desembarque, nosso turista solicita um táxi para que o leve ao hotel. Fica muito entusiasmado com o glamour dos carros luxuosos de marca japonesa. $O$ motorista o conduz em alta velocidade pelas ruas pouco pavimentadas da cidade, tirando do passageiro a oportunidade de apreciar as atrações turísticas a sua volta. Mas, tudo bem, diz ele - estou de férias! Fica, entretanto, um questionamento: será que a casa do taxista é tão luxuosa quanto seu carro? Resposta: não. Como será que ele faz para adquirir um carro desses? O trecho abaixo responde a esta questão:

O governo incentiva os bancos a disponibilizarem empréstimos para carros, mas empréstimos para casas não são facilmente disponibilizados; e se você perguntar novamente por que, você será informado que as duas principais concessionárias de veículos em Antígua são de propriedade em parte ou totalmente de ministros do governo (KINCAID, 1988, p. 7, tradução nossa). ${ }^{9}$

Notamos, assim, certa firmeza no posicionamento do narrador no que se refere ao desprezo generalizado pela forma como se dá a governança em Antígua. Uma minoria de pessoas ligadas ao governo usufrui de bens de consumo padrão internacional, enquanto todo o restante da população, formada em grande parte por pessoas descendentes de africanos escravizados, pena em meio às precárias condições de subsistência.

A narração prossegue com a personagem antiguana expondo algumas razões pelas quais aquele país estava naquela situação caótica a partir das seguintes provocações:

Em algum momento você já se perguntou por que tudo que pessoas como eu parecem ter aprendido de ti é como apreender e assassinar umas às outras, como governar mal mente, e como pegar a riqueza do nosso país e depositar em uma conta num banco suíço? Em algum momento você já se perguntou por que tudo que pessoas como eu parecem ter aprendido de ti é como corromper nossas sociedades e

\footnotetext{
9 "The banks are encouraged by the government to make loans available for cars, but loans for houses not so easily available; and if you ask again why, you will be told that the two main car dealerships in Antigua are owned in part or outright by ministers in government' (KINCAID, 1988, p. 7).
} 


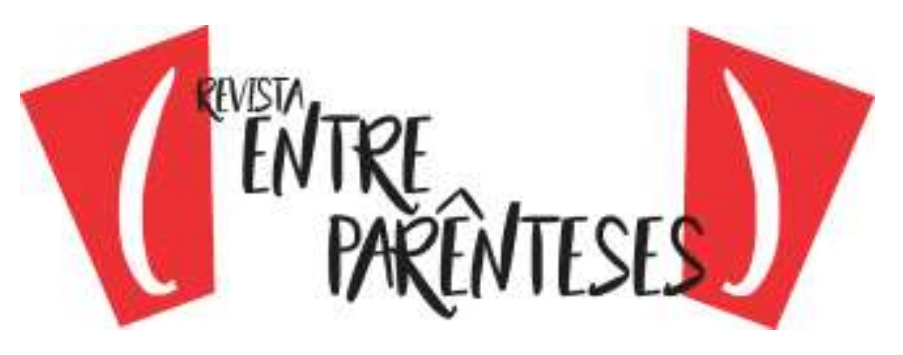

como sermos tiranos? Você vai aceitar que isso é em grande parte tua culpa (KINCAID, 1988, p. 34-35, tradução nossa). ${ }^{10}$

Ao fazer tais questionamentos, o narrador sugere e, em seguida, afirma que o perverso sistema de governança da ilha é uma reprodução do que a então colônia herda da sua metrópole. Descreve também a exploração insana pelos europeus dos recursos e dos habitantes de Antígua, numa tentativa de expor a perversidade e a falta de competência para governança por parte daquele povo. Finaliza dizendo que, após fazer esta tão complexa e de igual modo tão relevante reflexão, a primeira ideia que deve passar pela cabeça de um europeu ao pensar em antiguanos é a de que eles são "[...] os descendentes daquelas elevadas e nobres pessoas, os escravizados" (KINCAID, 1988, p. 80-81, tradução nossa). ${ }^{11}$

\section{CONSIDERAÇÕES FINAIS}

Assim, considerando as proposições feitas anteriormente, sendo filha adulta e independente, a colônia mostra para sua mãe, metrópole, que não mais está disposta a copiar e reproduzir modelos de uma cultura alheia ao seu modo de pensar e interagir com o mundo. Que sua cabeça, desconfortável com o feltro do imperialismo inglês, está em busca de chapéus mais adequados para lidar com o sol causticante das precárias condições da vida adulta enquanto filha explorada e depois abandonada pela mãe, sem que nada the fosse deixado como forma de ressarcimento pelos prejuízos materiais e imateriais causados no período de "convivência forçada", o da Colonização.

Em suma, a análise das duas metáforas conceituais - METRÓPOLE É MÃE; COLÔNIA É FILHA - acima descritas, tendo como base o contexto das

\footnotetext{
10 "Have you ever wondered to yourself why it is that all people like me seem to have learned from you is how to imprison and murder each other, how to govern badly, and how to take the wealth of our country and place it in Swiss bank account? Have you ever wondered why it is that all we seem to learn from you is how to corrupt our societies and how to be tyrants? You will have to accept that this is mostly your falt' (KINCAID, 1988, p. 34-35).

${ }_{111 "[. . .]}$ the descendants of those noble and exalted people, the slaves" (KINCAID, 1988, p. 80-81).
} 


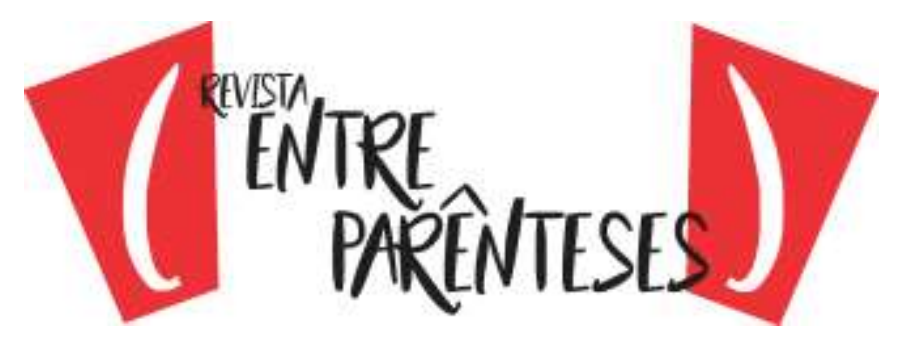

identidades caribenhas, mostra-nos de maneira bastante expressiva a relevância da linguagem e sua influência na forma como criamos significados no mundo a nossa volta. Nesse sentido, tomando como exemplo o modo como artistas caribenhos estão ressignificando as identidades desses povos na contemporaneidade, de forma autônoma e aberta a novas experiências culturais, o presente artigo sinaliza a necessidade de reflexões posteriores nas quais seja possível estabelecer um diálogo mais direto de tais identidades com novas possibilidades de se pensar as identidades brasileiras sob o ponto de vista pós-colonial global na atualidade. Espera-se que tais estudos posteriores possam promover o necessário exercício de alteridade nas diversas culturas brasileiras no sentido de refletir o quanto essas têm a oferecer e a apreender com as culturas caribenhas, além de colocar em perspectiva o grau de relacionamento intercultural que o Brasil estabelece com tais culturas no comparativo com as culturas europeias.

\section{Referências}

ANDERSON, Benedict. Comunidades Imaginadas: reflexões sobre a origem e a difusão do nacionalismo. Tradução Denise Bottmann. São Paulo: Companhia das Letras, 2008.

ARISTÓTELES. Das formas do nome; das figuras. In: Arte Poética. Tradução Pietro Nassetti. São Paulo: Martin Claret, 2003. p. 74-80.

CARRASCOSA, Denise. Traduzindo no Atlântico Negro: por uma práxis teóricopolítica de tradução entre literaturas afrodiaspóricas. In: CARRASCOSA, Denise. (Org.). Traduzindo no Atlântico Negro: cartas náuticas afrodiaspóricas para travessias literárias. Salvador: Ogum's Toques Negros, 2017. p. 63-75.

CRUZ, Décio Torres. Ilhas caribenhas de língua inglesa e seus escritores. In: Literatura (pós-colonial) caribenha de língua inglesa. Salvador: EDUFBA, 2016. p. 65-155.

FANON, Frantz. O negro e a linguagem. Pele negra, máscaras brancas. Tradução Renato da Silveira. Salvador: EDUFBA, 2008. p. 33-52. 
GLISSANT, Édouard. Línguas e Linguagens. In: Introdução a uma poética da diversidade. Tradução Enilce do Carmo Albergaria Rocha. Juiz de Fora: Editora da UFJF, 2005. p. 39-60.

HALL, Stuart. Pensando a Diáspora: reflexões sobre a terra no exterior. In: Da diáspora: identidades e mediações culturais. Tradução Adelaine Resende et al. 2. ed. Belo Horizonte: Editora da UFMG, 2013. p. 27-55.

KINKAID, Jamaica. On seeing England for the first time. Transition, Indiana University Press, Indiana, n. 51, p. 32-40, 1991.

Annie John. New York: Noonday Press, 1997.

A Small Place. New York: Farrar, Straus and Giroux, 2000.

LAKOFF, George; JOHNSON, Mark. Metaphor we live by. Chicago: University of Chicago Press, 1980.

The contemporary theory of metaphor. In: ORTONY, Andrew. (Org.). Metaphor and Thought. Cambridge: Cambridge University Press, 1992. p. 202-251.

Recebido em 20/07/2020

Aceito em 02/12/2020 